\title{
Review: nursing interventions increase smoking cessation rates in adults
}

Rice VH, Stead LF Nursing interventions for smoking cessation. Cochrane Review, latest version 21 May 1999. In: Cochrane Library. Oxford: Update Software.

\author{
QUESTION: What is the effectiveness of smoking cessation interventions delivered by \\ nurses?
}

\section{Data sources}

Studies were identified by searching the Cochrane Tobacco Addiction Review Group specialised register (which includes studies identified from Medline, EMBASE/Excerpta Medica, and PsycLIT, and by handsearches of specialist journals, conference proceedings, and bibliographies) using the terms nurse or health visitor. CINAHL was also searched from 1983 using the terms nursing, smoking cessation, and intervention.

\section{Study selection}

Randomised trials were selected if they evaluated the effectiveness of nursing smoking cessation interventions (defined as provision of advice or other information and strategies to help patients to stop smoking) for adults; had $\geqslant 2$ treatment groups; and had $\geqslant 6$ months of follow up. Studies were excluded if the sample included pregnant women, if they compared advice alone with advice plus nicotine replacement therapy, or if no outcome data were provided on smoking cessation rates.

\section{Data extraction}

Data were extracted on study setting and design, sample size, definition of a "smoker," description of the intervention and its intensity, outcomes, and biochemical validation. Main outcome was smoking cessation, defined using the strictest available criteria for abstinence (eg, sustained cessation rather than point prevalence). Studies were assessed for quality and rated for efforts to control for selection bias.

Sources of funding: National Health Service Research \& Development

Programme, UK

American Heart

Association, USA

For correspondence: Professor V H Rice, College of Nursing,

Wayne State University,

5557 Cass Avenue,

Detroit, $M I 48202$,

USA. Fax +1313577

5777.

A modified abstract

also appears in

Evidence-Based

Nursing.

\section{Main results}

19 studies met the selection criteria; 17 involved patients from hospitals or primary care settings and 18 involved adults with diagnosed health problems. 14 studies reported smoking cessation validated by biochemical analysis of body fluids or expired carbon monoxide.

Nursing intervention v usual care for smoking cessation at longest follow up $(\geqslant 6 \mathrm{mo}) *$

$\begin{array}{lllll}\text { Outcome } & \begin{array}{l}\text { Nursing } \\ \text { advice }\end{array} & \begin{array}{l}\text { Usual } \\ \text { care }\end{array} & \begin{array}{l}\text { RBI } \\ (95 \% \text { Cl) }\end{array} & \begin{array}{l}\text { NNT } \\ \text { (CI) }\end{array} \\ \begin{array}{l}\text { Smoking } \\ \text { cessation }\end{array} & 15.7 \% & 12.5 \% & \begin{array}{l}28 \% \\ (2 \text { to } 61)\end{array} & \begin{array}{l}32 \\ (17 \text { to } 250)\end{array} \\ \text { *Based on a random effects model. Abbreviations defined in glossary; RBI, } \\ \text { NNT, and Cl calculated from data in article. }\end{array}$

Meta-analysis included 15 studies $(\mathrm{n}=7912)$ and was done on an intention to treat basis. At longest follow up, patients who received advice from a nurse were more likely to stop smoking than those who received usual care (table).

\section{Conclusion}

Nursing interventions (primarily advice to stop smoking) increase smoking cessation rates among adults.

\section{COMMENTARY}

Rice and Stead's review of 19 articles and their conclusions provide intriguing information about smoking cessation counselling approaches delivered by nurses. They indicate that healthcare providers have an important role in developing and implementing smoking cessation interventions. They also contend that healthcare providers need to include smoking risk assessment for every patient. Finally, they recommend that additional research is needed on the systematic use of nurse delivered smoking cessation interventions. Because nurses are often the gatekeepers for people entering the healthcare system, they could easily incorporate smoking risk assessments. ${ }^{1}$

Other areas need to be considered when evaluating the conclusions of this review. These interpretations were made based upon 19 studies. Although this is a respectable number compared with other meta-analyses, it means that many of the subanalyses were based on only a small number of trials. This is a potential problem because some of the results of these subanalyses differ somewhat from those of the larger reviews. For example, a smoking cessation intervention as part of a multifactorial intervention was effective for patients with cardiovascular disease (3 studies) whereas the smoking cessation intervention alone was not effective for these or other patients admitted to hospital. Only 1 study included patients with cardiovascular disease who were not in hospital and reported a statistically significant relative risk and a barely significant risk difference.

$$
\text { Barbara Jones Warren, PhD, RN, CNS, CS }
$$
The Ohio State University Columbus, Ohio, USA

1 Warren BJ. Cultural competence in psychiatric nursing: an interlocking paradiom approach. In: Keltner NL, Schwecke LH, Bostrom CE, editors. Psychiatric nursing. 3rd edition. St Louis: Mosby, 1999:199-217. 